the freezing-point; and if we take the area of the water as about equal to that of the land, we shall have heat. enough to raise the whole Arctic ocean to a depth of full 180 feet more than $20^{\circ} \mathrm{F}$, , or to a mean temperature of $52^{\circ} \mathrm{F}$, and as this would imply a still higher surface temperature it is considerably more than I require.

Unless therefore Prof. Haughton can prove that the amount of ice now forming annually in the Polar regions is very much more than an average of five feet thick over the whole area, his own figures demonstrate my case for me, since they prove that the rearrangement of land and sea which I have suggested would produce a permanent mild climate within the Arctic circle and proportionally raise the mean temperature of all north-temperate lands.

Briefly to summarise my present argument :-Prof. Haughton's fundamental error consists in assuming that the true way of estimating the amount of heat required in order to raise the temperature of the Polar area a certain number of degrees is, first, to suppose an accumulation of ice indefinitely greater than actually exists, and then to demand heat enough to melt this accomulation annually. The utmost possible accumulations of ice in the Arctic area, during an indefinite number of years, and under the most adverse physzcal conditions imaginable, are to be all melted in one jear; and the heat required to do this is said to be the "accurate measure" of that required to raise the temperature of the same area about $20^{\circ}$, at a time when there were no such great accumulations of ice and when all the physical conditions adverse to its accumulation and favourable to its dispersal were immensely more powerful than at present!

When this fundamental error is corrected, it will be seen that Prof. Haughton's calculations are not only quite compatible with my views, but actually lend them a strong support.

ALFRED R. WALLACE

By the courtesy of Mr. Ingram I am enabled to say that the tree at Belvoir supposed to be Araucaria Cunninghami is in reality, as surmised by Capt. King, Cunninghamia sinensis. The Cunninghamia is a native of Southern China, whence it has been introduced into Japan. In this country it was originally grown under glass, but, as the instance at Belvoir illustrates, such protection is not absolutely requisite. The tree is however somewhat tender, and so far as I know has never produced its cones in this country in the open air.

As to the Bamboos bardy in this country, it may be well to warn those who are not familiar with the plants not to expect to see the gigantic and rapidly-growing grasses that go under this name in the tropics. Rarely indeed do they atlain in this country the dimensions even of the Arundo donax, so familiar to travellers in Italy. As accuracy of nomenclature is proved in this and the foregoing instance to be a matter of much moment, it may be well to say on the authority of the late General Munro that the Himalayan plant commonly grown in gardens as Arundinaria falcata is more correctly called Thamnocalamus Falconeri, that the Bambusa gracilis of gardens is the true Arundinaria falcata of the Himalayas, and that the Japanese Bambusa metaké is Arundinaria japonica. General Munro's monograph of this group is to be found in the twenty-sixth volume of the Transactions of the Linnean Society, part $\mathrm{x}, \mathrm{x} 868$, while his remarks on the cultivated species may be found in recent volumes of the Gardeners' Chronicle, particularly in vol. vi. 1876, p. 773

The simultaneous flowering of Thamnocalamus Falconeri a few years ago in all parts of Europe created much attention, and was indeed a remarkable illustration of hereditary tendency manifested under very varied climatal conditions. The flowering of this grass was by no means looked on with unmixed gratification, as it entailed as a consequence the death or protracted enfeeblement of the plant.

A visit to Kew or to any of our larger nurseries will suffice to show that there are other Bamboos (that is, grasses belonging to the group Bambusea, if not true Bambusas) which are hardy enough to withstand even such rigorous winters as those of $1878-9$ and $r 879 \cdot 8$ o.

MaXwell T. Masters

\section{Climate of Vancouver Island}

THE letters on this subject which have appeared in NATURE (vol. xxiii. pp. 147, I69), have reminded me of a "Prize Essay on Vancouver Island. By Charles Forbes, Esq, M.D., M.R.C.S.Eng, , Surgeon Royal Navy," which was published by the Colonial Government in 1862. It consists of sixty-one closely-printed octavo pages and eighteen pages of Appendix; the latter containing several Tables on the Meteorology of the Colony.

The following is a portion of the "Abstract of Meteorological Observations, taken at the Royal Engineer Camp, New Westminster, during the year $186 \mathrm{r}$, by order of Col. R. C. Moody, R.E., Commanding the Troops. Lat. $49^{\circ} 12^{\prime} 47^{\prime \prime}$ N., Long. $122^{\circ} 53^{\prime} 19^{\prime \prime}$ W." (p. 3, Appendix) :-

Max. temp. of air in shade at 9.30 a.m., July $9,74^{\circ} 3^{\circ} \mathrm{F}$.

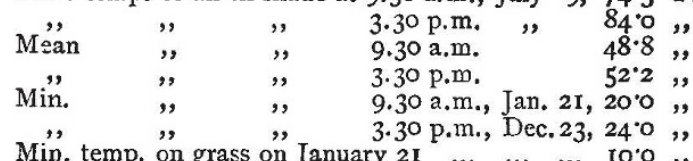

All the observations were made at $9.30 \mathrm{a} . \mathrm{m}$. and $3.30 \mathrm{p} . \mathrm{m}$. daily throughout the year.

Torquay, January 6

WM. PENGELLY

\section{Dimorphic Leaves of Conifers}

IT is now generally believed that some of the varying forms assumed by individual plants or animals in the course of their development are as it were the reflex of an ancestral state of things. From this point of view the different forms of leaves assumed by some Araucarias, as well as by many other conifers, become of particular importance. The Retinosporas now so common in our gardens and on our balconies represent an immature stage of some Thuya, the proof of which statement is occasionally furnished by the plants which suddenly assume the foliage characteristic of that genus. In various species of juniper, notably in the Chinese juniper, two forms of leaf representing the juvenile and the adult condition occur together on the same branch.

Assuming that the juvenile, or "larval" forms, as they have been called, do really represent previous conditions in the history of the species, it might be expected that some of the fossil coniferæe would be characterised by the possession of this larval foliage to the exclusion of any other. But if I mistake not both forms of foliage have been met with in fossil as in recent conifers, and the pedigree of these plants is by so much the more pushed back.

The resemblance in the form and arrangement of the adult leaves in some Thuyas and allied plants to the disposition of the leaves in Selaginella shonld not be overlooked in this connection nor the close resemblance between the foliage of some species of Lycopodium proper and the "larval" leaves of many conifers as above referred to. Maxwell T. Masters

\section{Dust and Fogs}

THE meteorological conclusions of Mr. Aitken's important paper, published in NATURE, vol. xxiii. p. 195, will, if adopted without further examination, even temporarily, exercise an unfortunate influence upon the present attempts to rid the atmosphere of our large towns of their ever-recurring fogs, glooms, and mists, and those conclusions certainly are not supported by such evidence as we already have as to the production of fogs on a great scale, however much indicated by experiments in the laboratory. It is stated that, "It having been also shown that all forms of combustion, perfect and imperfect, are producers of fog nuclei, it is concluded that it is hopeless to expect that, adopting more perfect forms of combustion than those at present in use, we shall thereby diminish the frequency, persistency, or density of our town fogs." Now, first as to frequency : what are the facts with regard to localities differing in their methods or materials for producing heat? Every one living in or near London knows that fogs, thick mists, and dark days are far more frequent within than without its circumference, and experiment has shown that sunshine is both less frequent and much less intense within the metropolis. And, according to $\mathrm{Mr}$. Aitken's theory, something of the same kind ought to be observed wherever large quantities of fuel are burned, whether smokeless or not. Thus, the large towns of the Continent, where wood and charcoal are in general use, would bave their peculiar urban fogs. But they are free from any fogs beyond those which are common to the country. And Paris, before coal was much used, ought to have been distinguished by more frequent fogs than the surrounding country. But it was not so marked out. No oasis of fog prevailed there when the sun shone brightly beyond its precincts, as in our own capital. And Philadelphia, which burns 